\title{
TITLE:
}

\section{AUTOMATIC PLANKTON SAMPLER WITH MULTIPLE NETS}

$\operatorname{AUTHOR}(S)$ :

Yamazi, Isamu

\section{CITATION:}

Yamazi, Isamu. AUTOMATIC PLANKTON SAMPLER WITH MULTIPLE

NETS. PUBLICATIONS OF THE SETO MARINE BIOLOGICAL LABORATORY 1960, 8(2): 451-453

ISSUE DATE:

$1960-12-20$

URL:

http://hdl.handle.net/2433/174642

RIGHT: 


\title{
AUTOMATIC PLANKTON SAMPLER WITH MULTIPLE NETS ${ }^{1)}$
}

\author{
Isamu YAMAZI \\ Seto Marine Biological Laboratory, Sirahama \\ With Plate XLI
}

For sampling plankton materials in lakes or seas it is often desired to take at various places and depths under natural conditions as far as possible: In most cruises during the vertical hydrological observations, there are no sufficient times and convenient methods to do the plankton sampling from various depths. It is thus necessary to save vertically the quantitative sampling from desired zones in a single haul. A new apparatus which is equipped with a submersible automatic pump to collect the plankton and water samples was deviced.

The design of the original type and improved type is shown in Plate XLI. The original type made early in 1959 is shown in Figs. 1 and 2. And the second one of an improved design recently made is shown in Figs. 3 and 4 . Here gives briefly its construction, method of working and advantages.

The sampler of a new design is also quite simple. Its main part consists of a cylindrical water-chamber $(B)$, which is $25 \mathrm{~cm}$ in diameter and $30 \mathrm{~cm}$ in height, and a number of storing nets $(N)$, having each a diameter of $2.5 \mathrm{~cm}$ and a length of $15 \mathrm{~cm}$ are hanging within it. The nets are arranged circularly on a stainless steel net-plate $(N P)$ from which is removable easily each of the nets by the rotation of a ratchet wheel $(T W)$ which is turned by the action of the piston $(P i)$ situated on the upper side of the net-plate. The number of nets equals the number of teeth of of the ratchet wheel.

The employed pump ( $P$ and $M$ ) couples to a completely, submersible electric motor which is fully used in deep water. It is mounted in a brass frame, $10 \mathrm{~cm}$ in diameter and $17 \mathrm{~cm}$ in length and has a $2.5 \mathrm{~cm}$ outlet and $2.0 \mathrm{~cm}$ intake. It is rated at about 25 liters per minute with no head. The type of motor is $100-110$ volt $\mathrm{AC}, 1 / 8$ horse power, water-filled and water-cooled home pump which is manufactured by the Ôsaka Kinzoku Kôgyô Company.

Usually we use the pump with $1 / 4$ horse power, when it is necessary to collect a large quantity of plankton. To escape the air in the pump system a small aperture is placed at the height $(A E s)$. The air bubbles in it are therefore easily eliminated as soon as the sampler is sunk into the water. The capacity

1) Contributions from the Seto Marine Biological Laboratory, No. 358.

Publ. Seto Mar. Biol. Lab., VIII (2), 1960. (Article 29) 
of water which is pumped up in regular time is at a constant between 80 and 110 volts. The intake of water $(W E n)$ is covered by a coarse of $0.7 \mathrm{~cm}$ meshes and removes large-sized pieces of detritus and of pelagic animals such as salps, medusae, etc. The suspension cable which holds the electric lines is 200 meters in length.

When the switch is on at the deck, the water containing plankton which flows from the pump into the piston cylinder $(P C)$ on the upper disc of the apparatus pushes through a piston $(P i)$ to the opposite side and then flows into a net. When the switch is off, the running water stops and the piston is pulled to the former state by means of the spring $(S)$ placed in the pressure chamber $(P C)$. By the motion of the levers $(L)$ connected with the piston shaft, one tooth of the ratchet wheel ( $T W$ ) which is sufficient to shift one of the newly arrived net of the net-plate comes under the water-pass from one to another. As soon as the former graduated net leaves the water-pass, the mouth is covered by the upper plate $(U P)$ and gripped also by a flat gum tube $(G T)$ to prevent the plankton in the escape.

In the second type of a new design, large specimens of plankton can be collected without injury, since they are stored in the net before the water flows into the pump as shown in Figs. 3 and $4(W E n)$. The mouth of the collected nets taking away from the female screws is covered with a cap respectively. They are stored into a formaline tank in that condition and also employed to extract the chlorophyll containing within the phytoplankton.

This new plankton sampler can be used vertically aboard an anchored vessel, especially from the bottom to the surface at desirable depths by turns, and also to obtain many measurements in a short period of time. On sailing vessel it is also used in horizontal collection at the surface layer continually for a long distance. The sampler is practically placed in a tank filled with water on the deck and hangs down the vacuum horse-pipe equipped with a hood-bulb on the apex into the water. At that time the machine is operated by a time switch.

As the temperature indicator $(T)$ and hydrophotometer $(P h)$ connected by a long cable $(\mathrm{Ca})$ to the potentiometers on the deck are also installed on the upper frame disc, sea temperature and illumination can be measured simultaneously. The equipment of $\mathrm{pH}$ meter, oxygen electrode and continuous recorder too are at present designing.

\section{Acknowledgments}

The writer is greatly indebted to the Managing Director Yûsirô SIRAISI, Mr. Kakubun Yosizawa, Mr. Jun'iti Sako and other research staff members of the Ôsaka Kinzoku Kôgyô Company in Ôsaka for their helps in the construction of this sampler. He is also indebted financially to the Foundation in Support of the Seto Marine Biological Laboratory and the Japanese National Commission for UNESCO for Grants-in-Aid in this device. 


\section{EXPLANATION OF PLATE XLI}

Figs. 1 and 2. Photographs of the original type of the automatic plankton sampler with 16 nets.

Figs. 3 and 4. Design of the second improved type with 24 nets to show the general principles of working. The thermister and hydrophotometer are shown on the upper disc of the frame (right).

\section{ABBREVIATION USED IN FIGURES}

$A E s$, air escape ; $B$, bucket ; $C a$, suspension cable containing the electric lines of motor and measuring devices attached ; $C V$, collecting vessel ; $G T$, flat gum tube; $L$, lever ; $M$, motor; $N$, nylon net; $P c$, pressure chamber; $P h$, photometer; $P i$, piston; $S$, spring; $T$, thermister ; $T W$, ratchet wheel ; $U D$, upper disc ; $W E n$, entry of water ; $W E s$, water escape; $W E x$, water exit ; $W N$, butterfly screw 


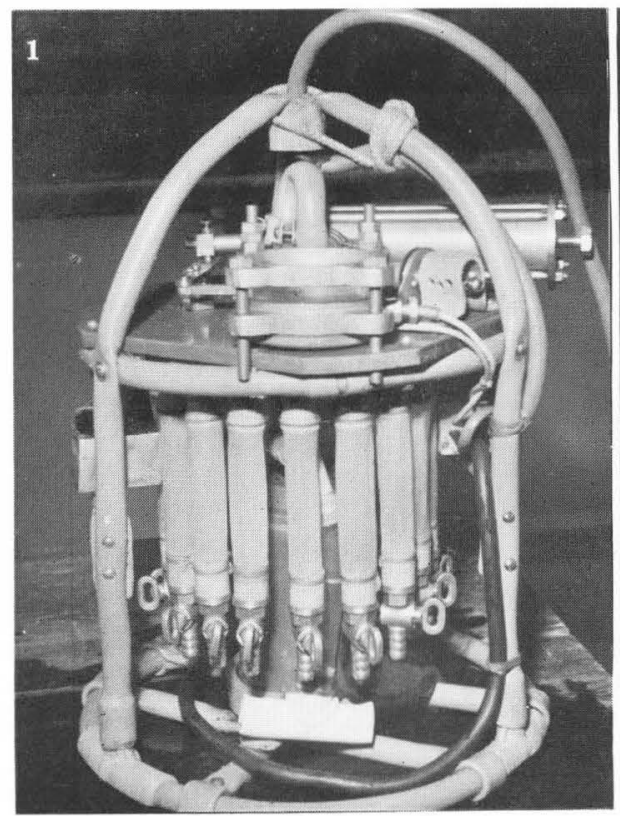

1

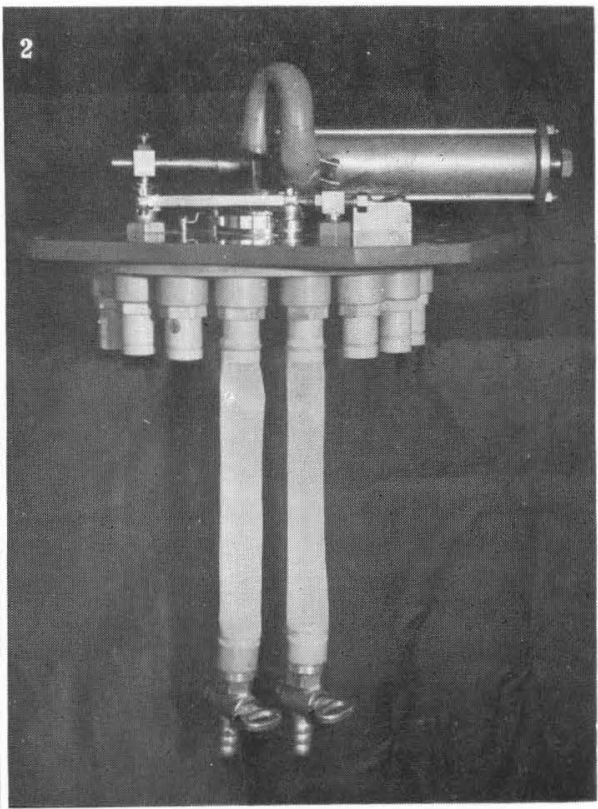

2

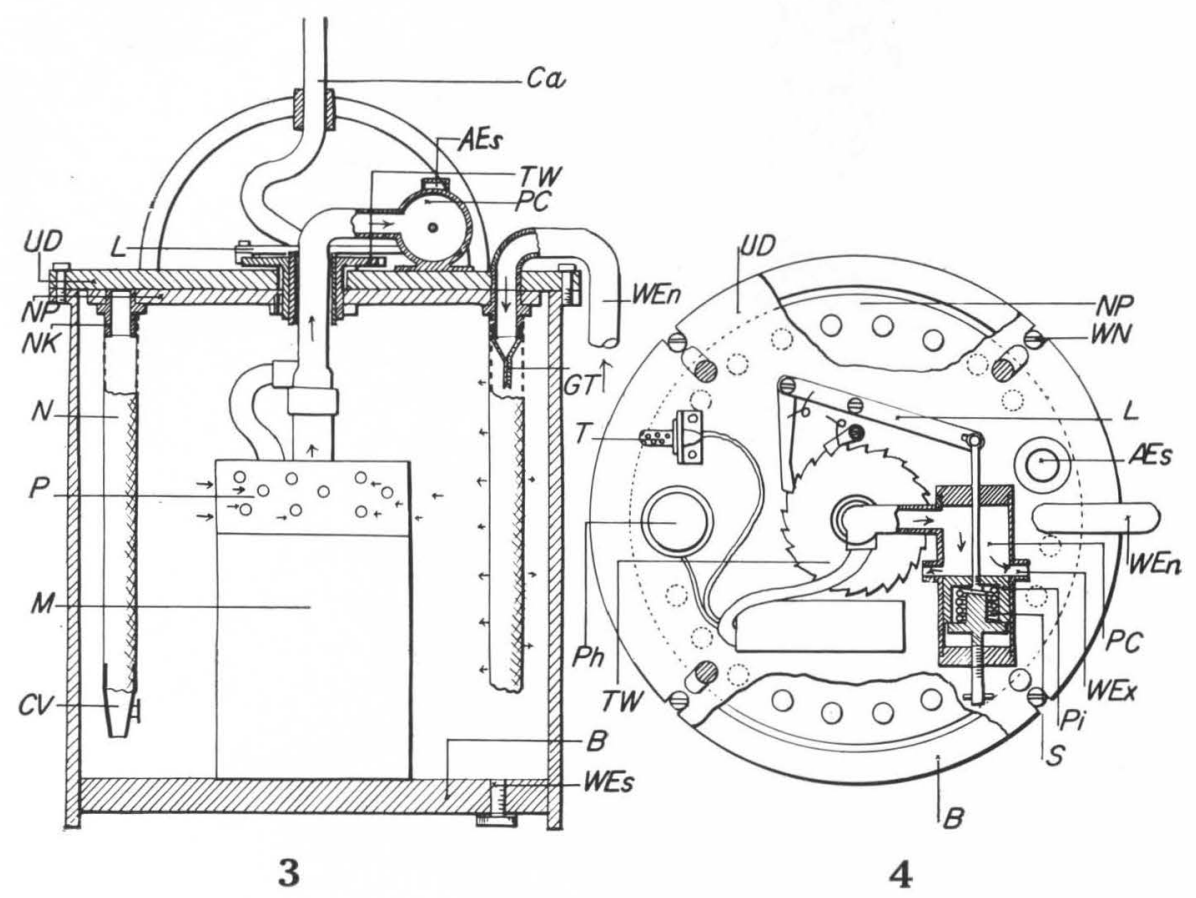

I. Yamazi: Automatic Plankton Sampler with Multiple Nets. 